\title{
From natural concepts to sustainable solutions in the built environment
}

\author{
D. Ibrahim \& H. Taleb \\ Sustainable Design of the Built Environment, \\ British University in Dubai, UAE
}

\begin{abstract}
Biomimicry is simply being inspired by nature and making maximum use of intensive research of what works and what is appropriate for this planet's various environments. This paper was inspired by the role of nature in solving our problems. First, case study problems were investigated and highlighted by conducting a survey in order to limit the scope of the research to specific strategies, which will be covered in the coming parts. Second was a search for the most ideal characteristics around us that endure the same climatic circumstances, asking how they survive and if such a function happening could be a clue to solving the deficiencies of the selected building. Salvadora persica has been chosen as the natural concept. An in-depth study of this plant will be presented along with suggested strategies that could be applicable to the built environment. A case study was selected - a campus in Ajman in the UAE. Detailed analysis was applied before and after applying environmental strategies. This paper proves that many environmental improvements may be achieved by using the biomimicry concept.

Keywords: biomimicry, Salvadora persica, acoustical analysis, thermal comfort, UAE, Ecotect.
\end{abstract}

\section{Introduction}

It has taken the human being a long time to figure out and study the link between how they survive or adapt during their lifetimes and how we can take advantage of this on earth [1]. Arnarson [2] mentioned that "The word biomimicry is composed of two words, one being 'bios' that means life and the other being 'mimesis' that means to imitate)" thus, the intersection between biomimicry and 
architecture can sustain our lives to a great extent by identifying one of these species, translating its behaviour, discovering the way it lives and finally evaluating the lifestyle. This paper was inspired by the role of the nature in solving our problems today. First case study problems have been investigated and highlighted by conducting a survey in order to limit the scope of research to specific strategies, which will be covered later in this report. Second was a search for the most ideal characteristics around us that live in the same climatic circumstances. This was resolved by asking how it survived and whether such functions happening could be a clue to solving the deficiencies of the selected building. Finally, it was necessary to solve the specific problems of the chosen case study sustainably by imitating the chosen natural concept and seeing how it adapts and survives in the surrounding atmosphere. Elaboration of the case study problems will be covered in sections 2,3 and 4, while studying the chosen natural organism will be in section 5, imitation and implementation using Ecotect simulation and a literature review will be discussed section 6 .

\section{Selecting a case study}

Ajman University Campus Architecture and Interior Design department located in Al-Jarf Ajman, UAE - has been chosen for a case study. It is geographically located at latitude (25.3885 degree) north of the equator and longitude (55.4454 degree) east of the prime meridian on the map of Dubai, Elevation above sea level: $16 \mathrm{~m}=52 \mathrm{ft}$.

The department houses 29 staff offices located on the left side of the Al-Jarf 2 building. Problems, which are frustrating and affect employees, may be summarised in three main points. First is a lack of daylight in the office area, second, the spread mould growth in ceiling tiles and finally how easy it is to get distracted in the offices because sound easily travels through the rooms. Studies show a great link between these three significant points and their impact on employee health and productivity. A fourth problem belongs to the outer space of the building; it requires more vegetation to preserve the ecosystem in the area.

According to Fisk [3] employee health can easily be affected by the surrounding indoor environmental quality (IEQ) and research has proven that productivity and well-being are very essential issues in professional and public health. On the other hand, negative IEQ could affect users physically in areas like respiratory illness and asthma through humidity, poor air quality and improper ventilation. Furthermore, stress and depression - which are examples of psychological health issues - are outcomes from poor lighting, inadequate acoustics and weak ergonomic design. Consequently, employees will be absent more, achieve less in working hours and be less productive individuals.

\section{Analysing Ajman's climatic data}

Considering Abu Dhabi's weather was the closest measure to study the climate in Ajman. In general Ajman's weather is moderate, as the temperature varies from $\left(10^{\circ} \mathrm{C}\right.$ to $\left.20^{\circ} \mathrm{C}\right)$ in winter while in the summer it is hot and humid, 
especially in the months of July and August $\left(35^{\circ} \mathrm{C}\right.$ to $\left.42^{\circ} \mathrm{C}\right)$. Further information has been analysed by visiting the Dubai Statistics Centre to compare the climatic changes from the year 2005 when the university was built to the present day (2014). Although there were no huge differences in temperature over that period, it fluctuated from $41^{\circ} \mathrm{C}$ to $44^{\circ} \mathrm{C}$ in July.

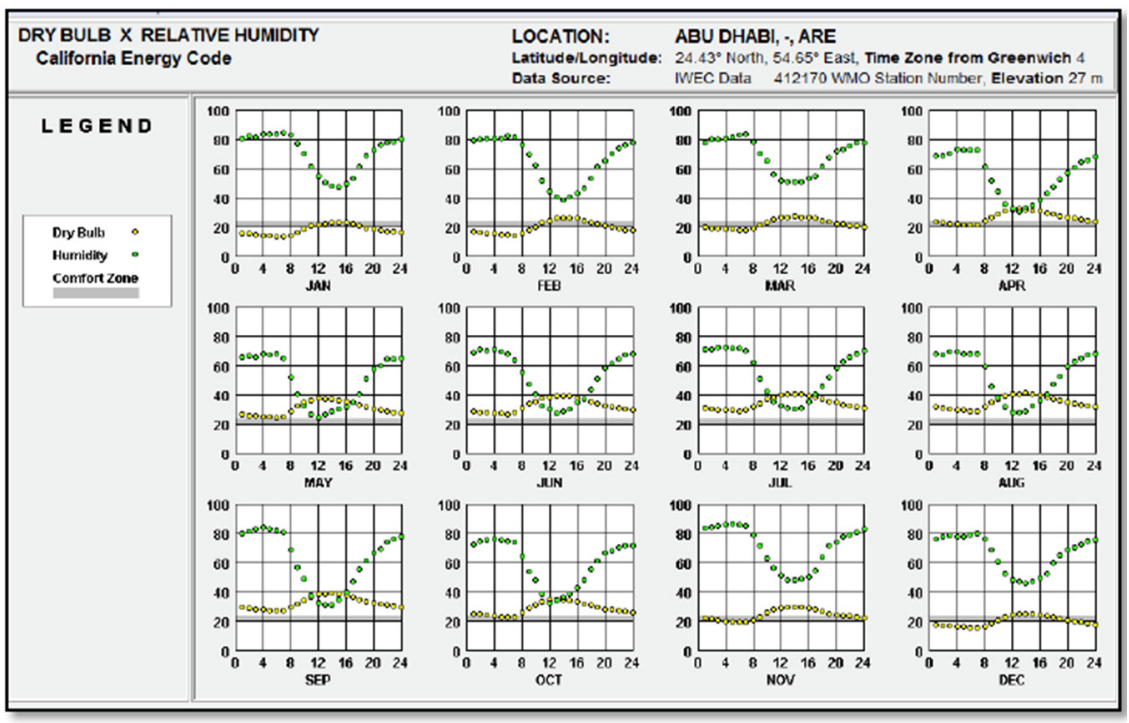

Figure 1: Relative humidity in Abu Dhabi.

This chart presents the humidity range by year; it fluctuates from about $80 \%$ as the maximum from midnight till early morning to decrease to reach $20 \%-50 \%$ during the rest of the year. Noontime in general is the time it decreases the most.

The Psychometric chart emphasises the need for cooling strategies - to reduce heat gain - while heating strategies are not necessary.

\section{Collecting data}

A "Comfort and Offices" survey was released in the department from 2nd March 2014, to investigate whether staff members were satisfied with their working environment or not. The survey consisted of three major productivity constraints which were; lack of natural daylight, noise pollution and the role of HVAC contaminants on health.

Staff members were requested to mention their gender at the top of the survey; Q.4 showed differences in answers (as shown in Fig. 3). The majority of females felt problems with fatigues and laziness $-46 \%$ and $40 \%$ respectively while only $7 \%$ had experienced eye strains and headaches. 


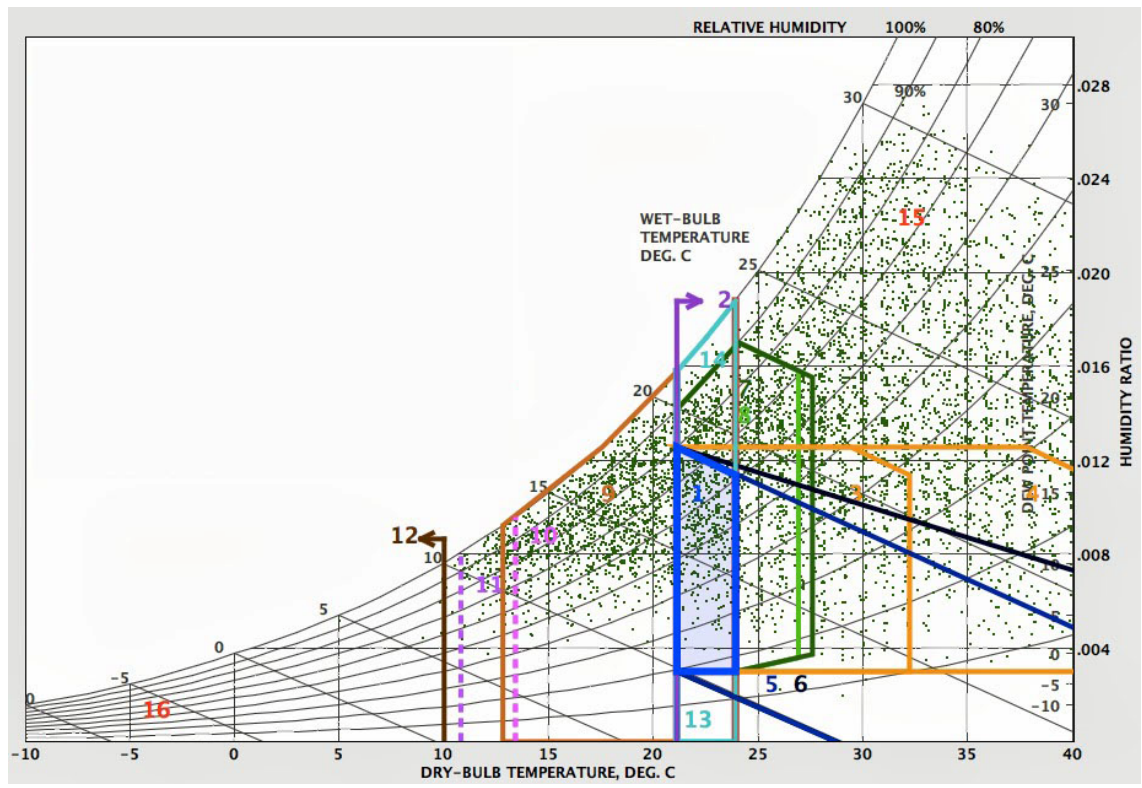

Figure 2: Psychometric chart for Abu Dhabi.



Figure 3: Artificial lighting impacts on females.

On the other hand males - presented in Fig 4 - showed almost the same percentage (22\%) experiencing eye strains and headaches, 19\% laziness and $4 \%$ dizziness but the majority felt fatigue (33\%). Most staff members strongly agreed that natural daylight plays a significant role in reducing the level of disease and improving their overall mood while working. 


\section{Q.4. Negative Impacts of Artificial Lighting on Male Staff Members?}

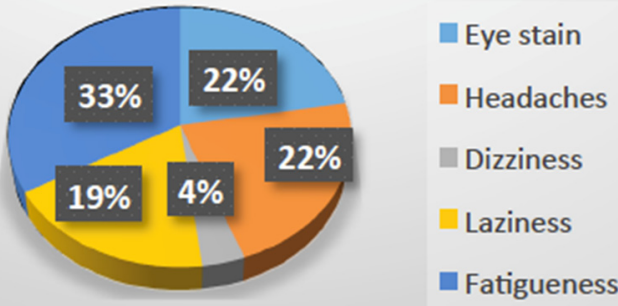

Figure 4: Artificial lighting impacts on males.

Furthermore, the impact of HVAC pollutants was also surveyed. The majority of staff had noticed biological contaminants appearing in the ceiling tiles from HVAC errors, although $3 \%$ of them had not. When asked whether they experienced any of the biological contaminant symptoms they responded as Fig. 5 illustrates.

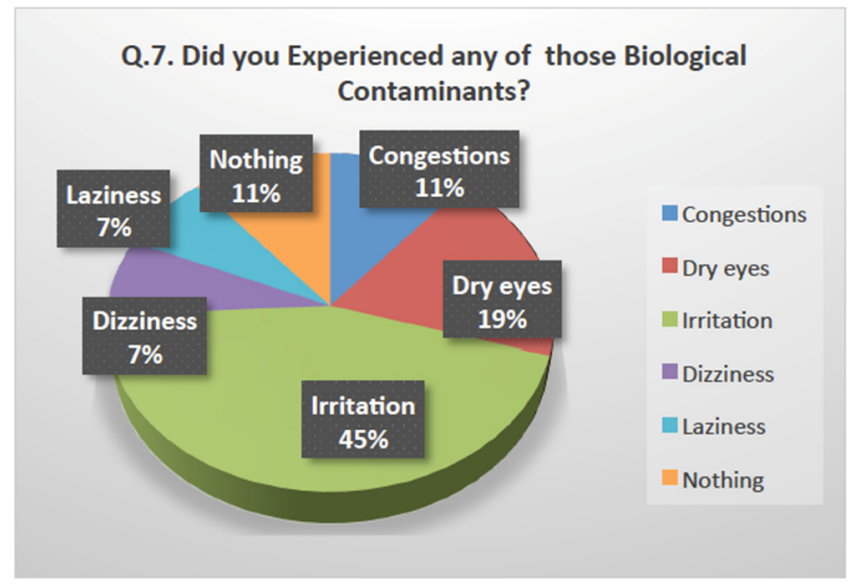

Figure 5: Symptoms from contaminants.

Irritation was the symptom most chosen by the staff members with $(45 \%)$, followed by dry eyes (19\%), then came congestion (11\%) and finally $7 \%$ of users experienced laziness and dizziness from biological contaminants. Notably, however, $11 \%$ of all occupiers felt nothing. 
More than $50 \%$ the staff members - as Fig. 6 shows - get distracted from work by surrounding noises in the department from 4 to more than 8 times a day, while the other $43 \%$ were distracted from 2 to 5 times a day.

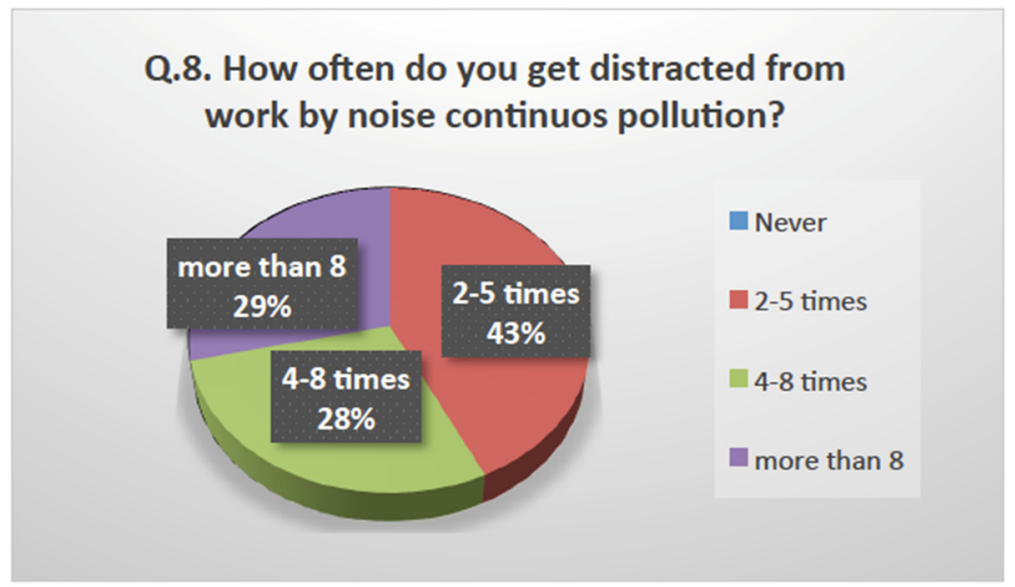

Figure 6: Distraction by noise around.

All occupiers emphasised the need for acoustical insulation in order to reduce noise in their offices so they can perform better. There was a need to improve the HVAC system to have a better IAQ, but the most essential need was to provide proper natural daylight to their workplace.

\section{Identifying a well-adapted biological element}

While searching for a spice that can survive and adapt in hot dry climate to suit the case study; Salvadora persica (SP) appeared. SP is a class of evergreen tree scattered across tropical Africa and Asia to Mascarene Island and China. It belongs to the family Salvadoraceae and the common name was given in 1749 in honour of an apothecary of Barcelona, Juan Salvador y Bosca (1598-1681), by Dr Laurent Garcin, botanist, explorer and plant collector [3]. 'Toothbrush tree' or 'Miswak' tree are also other terms [4], as in Arabic it means, "Sticks for rubbing the teeth". The Miswak was used by the Babylonians 7000 years ago, they were used throughout the Greek and Roman empires and have been used by Jews, Egyptians and in Islamic empires.

In the Holy Quran, it is one of the classified plants amongst the seventeen plants families that are cited [5]. Much research has been done into its antibacterial, antimicrobial, anti-caries and anti-plaque activity and according to Arora and Gupta [4] research has proven that in the Salvadora genus species, almost all of its parts are pharmaceutically essential. Its stem extracts contain anti-microbial, antispasmodial and anti-caries properties, while aerial parts 
contain anti-microbial activity Furthermore, Salvadora persica leaves hold benzyl nitrile (volatile oil).

\subsection{Why was SP an inspiration?}

1. It contains anti-bacterial and anti-microbial characteristics in its roots and antifungal action in its leaves (improving IAQ).

2. It is a fodder tree (preserving the ecosystem).

3. Pits connected to the xylem are like halls in walls where water is allowed to pass, yet bacteria and gas bubbles are not (enhancing daylight).

4. Corky tissues around (sound insulation).

5. Phloem and periderm are very necessary to the constant survival SP (thermal envelope).

\subsection{Anatomy of SP}

The following figures illustrate SP anatomy from which all the inspiration comes.
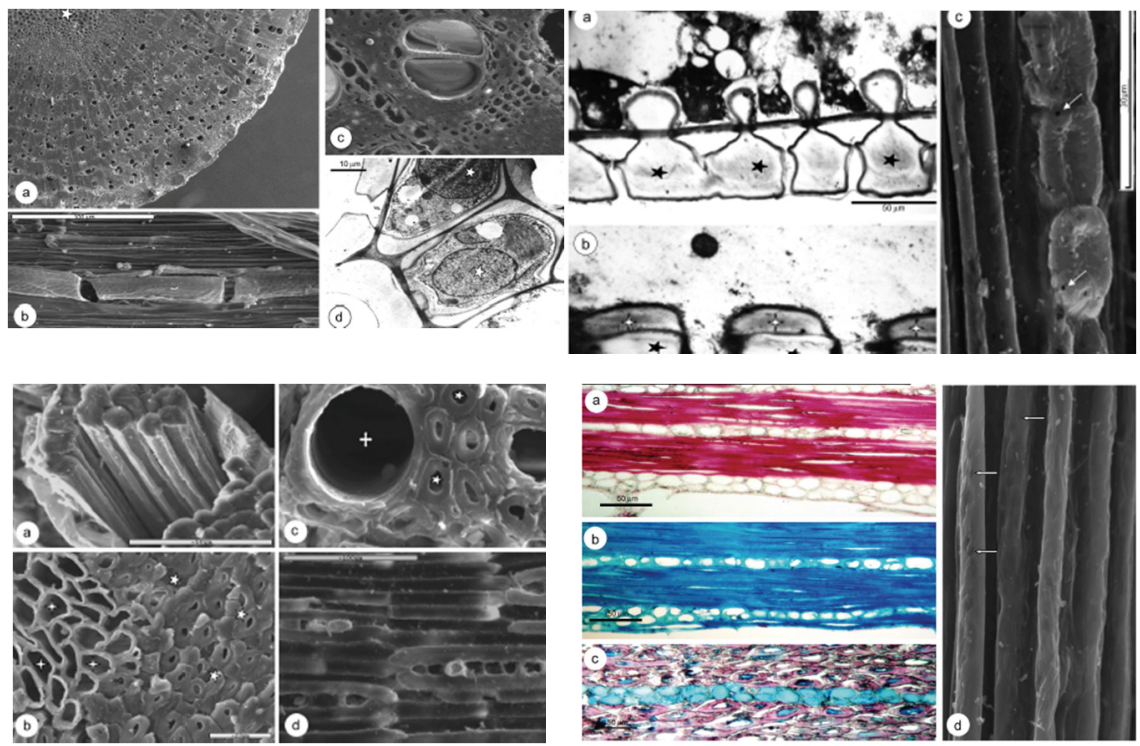

Figure 7: SP anatomy.

Fig. 7(a) (top left) shows a cross section of a young stem, the star indicates pith in the centre of the stem and (b) (top left) shows three disconnected parts of metaxylem and attached xylem fibres. Metaxylem occupied with balloon-like shapeless material.

Fig. 7(c) (top right) shows Xylem fibres connected with a group of ray parenchyma cells and limited pits which are highlighted with arrows on the cell walls. 
Fig. 7(a) (bottom left) shows a group of polygonal phloem fibres in thick lignified secondary cell wall with cortex and in (c) (bottom left) the stars refer to xylem fibres, but the quad arrow refers to metaxylem vessels.

Fig. 7 (d) (bottom right) shows how compressed net of longitudinal section in long xylem fibers, (up arrows) points at pits in the fibre cell walls.

\section{Bio-inspired strategies and Salvadora Persica characteristics}

In order to verify the ability of this tree the following was undertaken is to imitate and implement the characteristics of SP on the chosen case study and detect errors by using the Ecotect program and a literature review.

The interior design department, which consists of 29 staff offices, connects with two student areas left and right and was modelled with Ecotect.

First, the amount of natural daylight was calculated in office 260 and second noise reduction was been studied by means of literature review. Additionally, the outer space, which is part of the building envelope as well, was studied before and after adjustment.

\subsection{Daylight enhancement}

"Daylight is worth the money" as Edwards and Torcellini [7] said. Natural light has been proved to be useful for well-being and productivity if treated with proper installation and maintenance. Enjoyable surroundings will also decrease the stress levels for office users produced by natural lighting. Consequently, by improving worker health, employers will benefit financially.

For instance, according to Edwards and Torcellini [7] a study showed that employees in buildings without windows were less satisfied with their job and were considerably less positive. The absence of a 'light vitamin' can cause illlighting syndrome' varying from minor sleep and performance problems to serious depression, so producing healthy indoor lighting can simply form preventive medication and provide a new challenge for the lighting community [8]. Inspiring biological characteristic. Xylem, in this tree, does a vital job as it passes water and dissolved ions from the roots to the stems and leaves. "Holes in the wall" is an expression used to illustrate how the pits [9], which are only connected to the xylem's vessels actually function and the importance of their presence as they may differentiate between the flow of water versus the flow of atoms in the xylem: low molecular solutes as well as water are allowed to pass, bacteria and gas bubbles are, however, not [5] as shown in Fig. 8. From the same concept came the idea of using solar light tubes as it provides the same function. Holes in walls allow natural daylight to parts of the buildings without increasing heat gains and affordability as well [10]. It is a keen technology that takes natural lights one more step by refracting, reflecting and concentrating solar light into a small tube containing mirrors and lenses. In the chosen department all offices lack natural day light except numbers 259-5 and 233-7. Fig. 8 shows how office 260 is very gloomy, thus adjustments need to be done. As is clearly shown in Fig. 9, after using light-tubes the chosen office benefits from the natural daylight which can positively affect health and performance. 


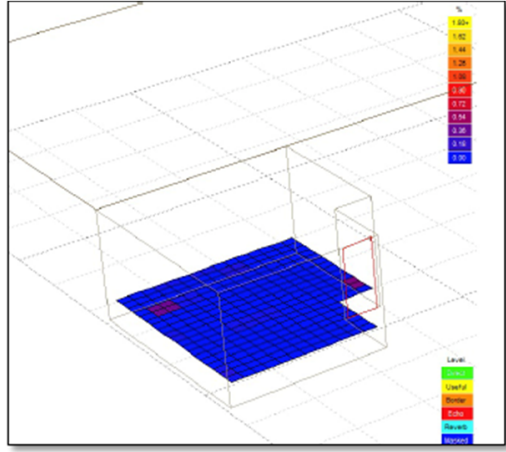

Figure 8: Office 259-5 before.

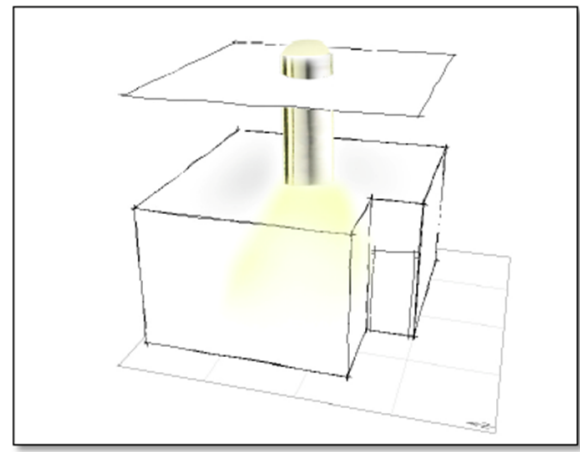

Figure 9: Office 259-5 after.

\subsection{Noise reduction}

Noise pollution due to the existence of students around the department affects staff concentration which consequently affects their productivity as has been seen in many previous studies. By reducing noise, job satisfaction will be one of the achievements made.

\subsubsection{Inspiring biological characteristic}

The water storage capacity of lignified xylem fibres in the stem tissues acts as the major factor of the core strategy observed in tropical trees adapting to extraordinary seasonal drought. Furthermore, the stem of the SP is on the outer surface which contains a thick periderm that is broken up at points around the stem and increase as the shoot grows due to the stretching of the outer surface (as seen in Fig. 10). The corky tissue is lightly linked to cells enclosed by an

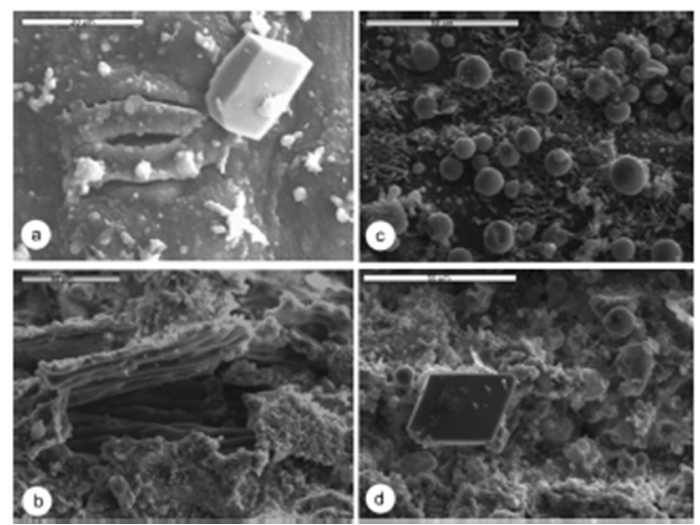

Figure 10: Corky tissue linked to cells in SP. 
intercellular air space [4]. Cork is a perfect solution for thermal and sound insulation. When overloaded, the cell walls bend or buckle, supplying large recoverable defluxions and large amounts of energy absorption.

The plant itself may be a solution for noise reduction. There are many ways that plants can reduce noise. First by sound absorption, as plant parts such as stems, leaves, branches and wood absorb sound. Deflection is the second method that may refract it.

\subsection{Wall insulation}

If wall insulation is improved, heat gain and heat loss will also be reduced, which will significantly reduce the monthly heating and cooling load on HVAC system. To improve the current building envelope, one suggestion is to replace as well the existing wall material which consists of rammed earth $500 \mathrm{~mm}$ with a $\mathrm{U}$-value of approximately $3.0 \mathrm{~W} / \mathrm{m}^{2} \mathrm{k}$ for which the monthly heating and cooling load was $101839184 \mathrm{MWh} /$ year (as shown in Fig. 11).

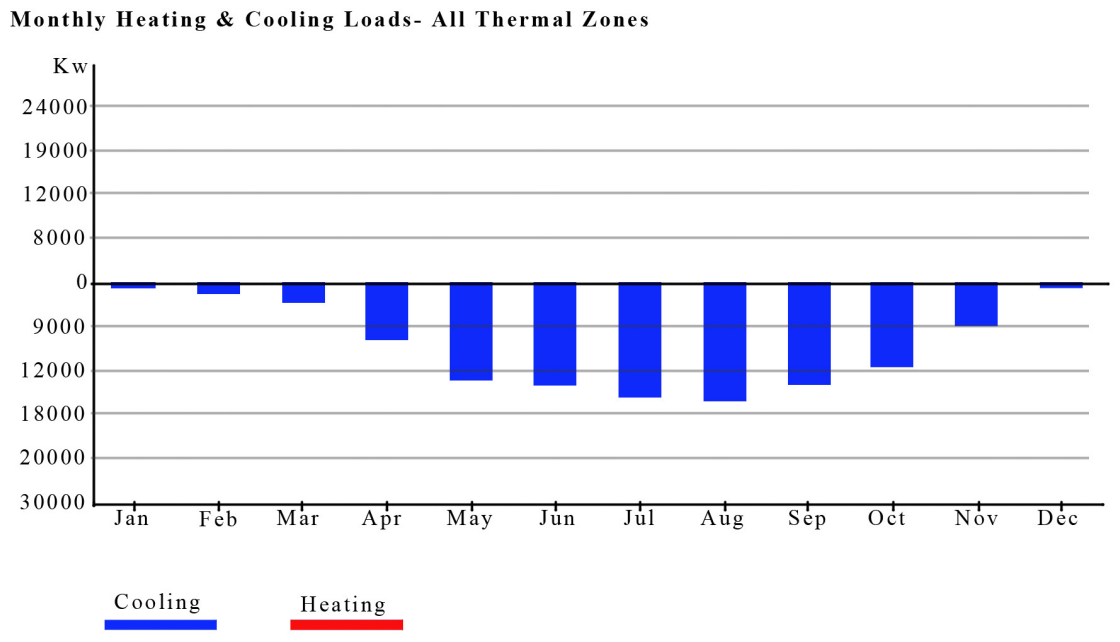

Figure 11: Before wall insulation improvement.

Applying better wall insulation to the existing wall, replacing a brick temper frame with U-Value $1.77 \mathrm{~W} / \mathrm{m}^{2} \mathrm{k}$, a calculation of the monthly heating and cooling load with same conditions shows the results were reduced to reach $705478238 \mathrm{MWh} /$ year (as shown in Fig. 12). 


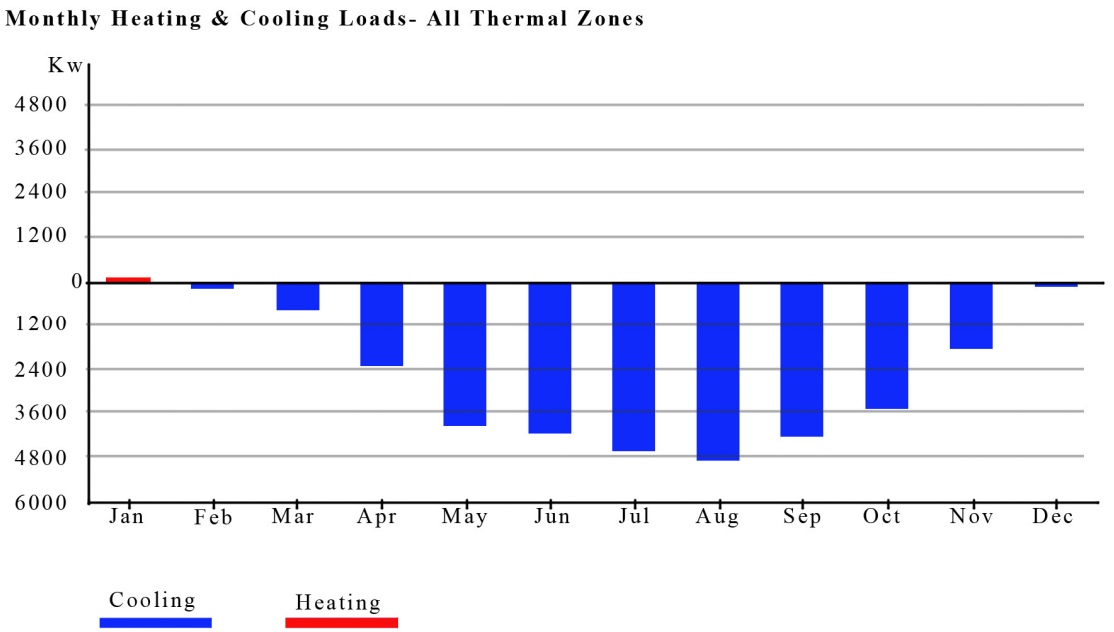

Figure 12: After wall insulation improvement.

\section{Conclusion}

IEQ is a term where many mechanical and natural factors combine together to achieve the desired environmental quality and comfort zone. Factors such as natural daylight, a space free of noise and clean air to breathe can affect dramatically the occupants of a space both psychologically and physiologically, which consequently increases their productivity, the level of their job satisfaction and their wellbeing. After analysing one of the species which is SP and by imitating how it survives, firstly, the pits that connected to the xylem as halls in walls to allow water to pass but not the bacteria were as an inspiration to use solar tube to access day light to the gloomy places. Secondly, the corky tissues in SP were as a solution for the disturbance in the department. Lastly, by coping the same procedure that the Phloem and periderm parts are doing for the constant survival for SP, wall insulation were used to protect the building. Lots of solutions have been provided in order to solve the case study problems and provide satisfaction to the users in the chosen department.

\section{References}

[1] Worldchanging.com. 2014. WorldChanging Seattle: Lecture Notes: Biomimicry in Architecture. [online] Available at: http://www.worldchanging.com/local/seattle/archives/008117.html [Accessed: 1 Mar 2014].

[2] Arnarson, P. (2011). Biomimicry. Reykjavík University. 
[3] Fisk, W. J. 2000. Estimates of potential nationwide productivity and health benefits from better indoor environments: an update. Indoor air quality handbook, 4.

[4] Arora, M. and Gupta, V. 2011. Phytochemical A_D Biological Studies on Salvadora Persica wall: a review. Pharmacologyonline, 1: pp. 591-601.

[5] Sawidis, T. 2013. Anatomy and Ultrastructure of Salvadora Persica Stem: Adaptive to Arid Conditions and Beneficial for Practical Use. Acta Biologica Cracoviensia Series Botanica, 55 (2), pp. 1-11.

[6] Korejo, F., Ali, S. A., Tahir, S. S., Rajput, M. T. and Akhter, M. T. 2010. Comparative morphological and biochemical studies of salvadora species found in Sindh, Pakistan. Pak J Bot, 42 (3), pp. 1451-1463.

[7] Edwards, L. and Torcellini, P., 2002. A literature review of the effects of natural light on building occupants. 1st ed. Golden, CO: National Renewable Energy Laboratory.

[8] Begemann, S., Van Den Beld, G. and Tenner, A. 1997. Daylight, artificial light and people in an office environment, overview of visual and biological responses. International Journal of Industrial Ergonomics, 20 (3), pp. 231-239.

[9] Thorne, E. T., Young, B. M., Young, G. M., Stevenson, J. F., Labavitch, J. M., Matthews, M. A. and Rost, T. L. 2006. The structure of xylem vessels in grapevine (Vitaceae) and a possible passive mechanism for the systemic spread of bacterial disease. American journal of botany, 93 (4), pp. 497504.

[10] One Block Off the Grid: The Smart New Way to Go Solar. 2014. One Block Off the Grid: The Smart New Way to Go Solar. [online] Available at: http://howsolarworks.1bog.org/solar-tubes/ [Accessed: 2 Mar 2014]. 